\title{
Role of Social Networks in the Spread of the Arabic Revolutions
}

\author{
Ehsan Madmalil $^{1,2}$, Hamed Mohagheghnia ${ }^{2}$
}

Received: 30.07.2015

Revised: 28.09.2015

Accepted: 5.10.2015

\begin{abstract}
Recent political developments in the Middle East and North Africa have been occurred in the globalization era. With the advent of globalization and the information revolution, human relations have been greatly altered. The impact of these developments is in such a way that the policy can be analyzed and classified into the periods of before and after the advent of the information technology. Accommodating a wide range of social and political actors in cyberspace, internet and social networks are means to advertise and promote political, social and cultural entities on the one hand and provide a source of political and social awareness on the other hand. They link the political activists to people, and finally provoke the actions of protest and mobilize protests. Hence, the role of the new social media such as the internet and social networks in the acceleration and continuity and expansion of the revolutionary developments in the Middle East and North Africa cannot be ignored. The role of the internet and new media in these revolutions has been so strong that some of them are called revolutions of Facebook and Twitter. Thus, in order to access the right results, you should understand the features and functions of social media, analyze their role in the development of revolutionary upheavals in the Middle East and North Africa. The current study is trying to explain the effect of social networks in the context of globalization on the formation and expansion of recent political developments in the Middle East and North Africa, for instance, in Tunisia, Egypt and Bahrain.
\end{abstract}

Key words: globalization, social network, internet, Arabic revolutions, Islamic awakening, Arabic spring.

\section{Introduction}

History of the Middle East and North Africa shows that participation of people in the streets is more to express anger and hatred towards foreigners and foreign colonizers, but this time it is different, and anger is towards domestic tyranny. "Ash-shab yurid isqat an-nizam" (The people want the fall of the regime), "E'tesam, E'tesam" (strike, strike), are the main revolutionary slogans shouted in Arab countries in recent developments. After beginning of "developments in the Arab world", two different interpretations were made about the developments. In the first interpretation that was emphasized by the liberal streams, these developments are called the fourth wave of democracy and Arabic spring. But in the second interpretation that arises mainly from the Islamic streams, developments in Arab countries are called the Islamic Awakening (Haji Naseri and Asadi Haghighi, 2012: 214-215). The purpose of this article is not to review the existing interpretation of these developments and postpones this issue to another opportunity. However, on December $17^{\text {th }}, 2010$, in Sidi

Bouzid, Tunisia, the police confiscated the vegetable cart of a young person. Mohamed

Author's Address

1 Khozestan Science and Research Branch, Islamic Azad University,Ahvaz,Iran

2 Department of Political Science, Ahvaz Branch, Islamic Azad University, Ahvaz,Iran.
Bouazizi was humiliated by the incident; he went to a local government building and set fire to himself. This event is a prelude to massive political protests that had eventually led to the fall of Ben Ali in Tunisia. This event profoundly influenced the Arabic societies, so that later, Hosni Mubarak in Egypt fell from power and the range of the protests, achieved several countries such as Libya, Bahrain, Yemen, Jordan and Syria. In terms of the roots of these developments and changes, some focused more on political factors such as the lack of democracy and freedom, and some focused on economic factors such as poverty and unemployment, and some have tried to provide a consolidated framework to explain the developments. But with a little tolerance, perhaps the most important features of the recent developments in the Arabic political systems can be classified as authoritarianism and personalization of power, partisan dictatorship, corruption, secularism, apparent democracy and political repression and lack of modern and efficient civil institutions (Abolfat'hi and Nouri, 2012: 52). Revolutions happened in the Arab world are affected by several variables, among which the current paper put emphasis on the variables of information technologies and particularly social networks in the development of political developments in the area. One of the important aspects of the formation and expansion of the developments in the Middle East and North 
Africa, is the role of new communication technologies, internet and social networks. The effect of communication media, particularly social networks in notification and the rapid spread of revolutionary developments in the region is undeniable. The question is that "What is the role of social networks in the spread of the Arabic revolutions?". In response to this question, the assumption is that "the internet and especially social networks, increased the awareness among people and social forces involved in the region, particularly young people, and drew their attention to what was going on around them and facilitated and accelerated the process of regional developments." In the present study, first, the theoretical foundations are stated and then, the independent variable of the discussion, the social network and its functions in globalization are discussed. Arabic revolutions and the nature of these developments will be discussed in the third section. Finally, the paper examines the main issue of this paper, the role of social networks in the spread of Arabic revolutions. Presentations end with conclusions.

\section{Research Theoretical Foundations}

Any phenomenon and reality must be placed in a theoretical framework or a coherent format so that we can examine the subject in a coherent and systematic way and show the relationship between the different parts. Since the early 1970s, new information technologies have increased the vulnerability of government. The Swedish government report called "Tengline Report" emphasizes that major risks of network society can threaten the life of the countries, because the internet, individuals and groups from around the world, are connected to each other and exchange the communication information. Global Information Society has greatly changed the concept of security and this change is to create a cyberspace threatening most countries. So cyberspace is not only a digital communication infrastructure, but also an ocean of information that humans develop and control its infrastructure (Eriksson and Giacomell, 2007: 3). In this regard, the information revolution in the virtual world increasingly developed the role of non-profit organizations and companies, social movements and network activities, and these are the non-state actors who have created a new challenge for traditional societies as a new online class, with a new discourse, and with young audiences. This symbol of this postmodern society is the digital age or the internet virtual world. Internet has made a new identity in the virtual world. In this space, "Webb" believed that the boundary images of cyberspace, is a sign of a postmodern shift from a human-restricted human to a non-restricted human equipped with computer (Ebrahimi, 2011: 114). "Jean Baudrillard", a post-modern writer, has an analysis of modern society that shows how the virtual fact can form the real fact. He believes that in the modern age, computer simulations, data processing, media and organization of society based on signs simulation models become increasingly important. They give consistency to the new social order and signs are governing the social life. Suggesting the concept of "Hyper reality", Baudrillard believes that in these circumstances, the unreal fact is more real than the reality itself, namely the fact that is artificially produced, is more real than the real. Thus, Baudrillard shows how signs and images act as control mechanisms in the contemporary culture. Although he considers the power so diffuse and abstract that it cannot be followed, and basically believed it is impossible to fight against it, his understanding is important in terms of the attention to new dimensions of society and power that can be seen in the media and signs (Moshirzadeh, 2006: 56). Accordingly, with the arrival of various social networks and websites in the Arab world, the situation in the world has been surprisingly changed by a population about sixty-one percent of young people. Arabic revolutions experience the post-modern at the same time through the new technologies. Live pictures of squares in the revolutionized countries such as the "Al-Tahrir" in Cairo, from networks such as Al Jazeera, exported the excitement of the squares to the world and reflected a hyper real situation. Then, in order to make the role of social and satellite networks in Arabic revolutions more objective and the production of a real fact by a virtual fact, we further review such developments in Tunisia, Egypt and Bahrain.

\section{Globalization and the Rise of Social Networks}

"Globalization" should be seen as a process that influences all aspects of human life, including political, economic, social, private and even spiritual. Globalization process is usually studied in four areas of economic, political, cultural and technical. Today, the concept of globalization as one of the important processes of social and 


\section{Role of Social Networks}

political life has become one of the key issues is the social sciences, due to the its growing influence in various fields. Globalization is a concept that is partly related to the issue of global integration and the global village on the one hand and modernism and postmodernism issues, on the other hand. In this regard, "Malcom Waters" sees globalization as a social process that leads to the weakening of the geographical, social and cultural conventions borders, in a way that people become more aware of the weakness of borders (Waters, 2000: 12). Robertson believes that "globalization is a concept to explain the current reality in the world and also represents a kind of awareness and perception of the world that considers it as a whole" (Robertson, 1992: 6). This article focuses on the technologic aspects of globalization. It talks about the third industrial revolution in technical and technological fields. The third Industrial Revolution at the end of the twentieth century, has brought a fundamental transformation in the field of communication, consumption and information. This is what some writers call it "Electronic Global Village". The emergence of new technologies such as the internet, satellite, mobile, social networks have been named as the consequences of globalization in the technical field. The purpose of globalization technologic process is the development of mass communication technology, especially information technology. One of the most important benefits of this technology, is the exchange of ideas and beliefs that are easy to take. The distances of time and place lost their importance due to communication technologies. The internet is the most important example for the fact that how the world is moving toward being smaller (Bashiriyeh, 2000: 10-13). In fact, with the advent of globalization, the use of the internet is expanded in all political, economic and social areas in developed and somewhat in developing countries. Due to the increasing influence of the internet in today's world in different aspects, terms like "global village", "planetary awareness" and the "end of geography" spread in the academic circles. Today, it is said that politics move on the media wing, and gets more important as increased use of civil society actors in the infranational, national, regional and global levels from the internet and their role in political communication and political challenging (Sardarnia, 2008: 154). Accommodating a wide range of social and political actors in cyberspace, internet and social networks are means to advertise and promote political, social and cultural entities on the one hand and provide a source of political and social awareness on the other hand. They link the political activists to people, and finally provoke the actions of protest and mobilize protests. Therefore, we can say that the internet is the most important sign of symbolic, identifying and advertising power in the new era, and politics and political developments are dependent on the pervasive media to a considerable extent. In this framework, virtual social networks are a new generation of internet websites. In these websites, internet users virtually get together around a shared axis and constitute the online communities. In fact, social network, is a website or a set of websites where users can share their demands, interests, ideas and works with others. In the last couple of decades, social networks have been developed with an unprecedented speed. Social networks such as Facebook, Twitter, YouTube, Google etc. are new grounds for the creation of virtual networks among people and have expanded tremendously in a short time. According to the type of their activity, social networks have options such as internet news, online games, ability to upload videos and other media files and communication with other personal computers (Aghaei and others, 2012: 11-12). In order to access the main objective of the research in understanding the role of the internet and social networks in the developments of the Middle East and North Africa, we consider some of the most important functions of social networks.

One of the features of social networks is reshaping the discourse communications. At the end of the first decade of the twenty-first century, social networks such as "Facebook", "Twitter" and "YouTube" have changed the landscape of social interaction and communication between people. According to experts, communication, social networks further reduce face to face relationships and contribute to the development of digital and virtual relationships (ibid: 13). New media and social networks play the role of informing, coordinating and linking people. The internet and social networks by compressing time and space, have unprecedentedly accelerated the inter-organizational linkages between activists and supporters of the protests that are geographically apart from each other. Development of information and communication technologies such as social networks was so rapid 
and widespread that made the people in all parts close together and made their understanding more similar. In fact, in the era of globalization, media and social networks have a special place in the world and are the reason of many of the developments that have ever existed. The media and social networks have transnational nature and no border that currently made them easy to access (Rafi and Janbaz, 2010: 80-81). Also, today, social networks with rapid notification on acute problems of human society, transmission of protest symbols and sensationalism, foment the widespread protest action. However, it should be stated that the internet and social networks are the most important signs of symbolic, identifying and advertising power in the new era, and politics and political developments are dependent on the pervasive media to a considerable extent. In fact, nowadays modern information and communication technologies, especially the internet and social networks have become important resources for mobilizing collective action and the innovation thereafter, organization and action of social movements around the world. In this regard, the Arab youth built worlds for themselves through technology media such as the internet and social networks, though there were no real objects but they had real effects. After a while, distribution of videos and photos of tragic self-immolation of a young vegetable seller on social networks, people got together as scattered gunpowder particles and removed the petition of the dictatorship (Kia and Mahmoudi, 2011: 17). A more analytical study of this issue is provided in the following, but before that, it is necessary to discuss the dependent variable of the discussion namely the nature of revolutionary developments in the Arab world.

\section{Nature of political developments in the Arab world}

Political developments in recent years in the Arab world, showed that the discourse in these societies are not able to provide logical and convincing responses to community issues and questions of other discourses and the time has come for change in discourse and conceptual frameworks. The Arab world is experiencing a deep identity crisis and social, political and economic unrest. Marginal discourses have limited the area for the dominating discourse and challenged their principles and efficiency in the social field. Now it is the time for transition period between discourses and within them, and brokers are trying to reconstruct their identities and social meanings through classification and identification by alternative discourses (Yazdanfam, 2011: 57). In this process, the dominant discourses and identities are removed and identities may become the dominant discourse in these societies. Among them, two democratic and Islamist discourses were the marginal discourses which stood against the discourse of Arab political systems authoritarian and are now looking to establish their discourse semantic systems. Various ideas have been presented on the nature, background and implications of recent developments in the Middle East and North Africa; some of these developments were called the Islamic Revolution and some liberal and democratic revolutions; some put more emphasis on protests economic roots and some believed that the political factors are the main reason of the recent developments. Then we try to briefly discuss the main ideas that have been proposed about the nature of recent developments.

Political developments of the Arab world as a revolution and Islamic Awakening

Some scholars and experts believe that recent developments are undoubtedly in line with the "Islamic Revolution" and is affected by the religious movement in Iran in 1979. In fact, most American republicans had such perception and the Islamic Republic and its leaders deal with the Arabic revolutions in the framework. So we should emphasize the role of Islam and its teachings as the behavioral norms and rules in the development of the identity of the region's peoples; this identification of Islam causes a different definition as friend, foe or competitor and determines the boundaries between themselves and outsiders. Thus, it can be argued that some radical Islamic norms and teachings, including resistance, martyrdom, fighting against oppressors and infidels, renouncing mustache, chanting God is great, etc. with the construction of a revolutionary Islamic identity for the nations of the region, have shaped the interests and protest actions of them. Accordingly, and more based on constructivist approaches, these developments are defined as Islamic revolutions and concepts such as Islamic Awakening (Rasouli Sani Abadi, 2013: 232).

Political developments of the Arab world as liberal democratic revolutions

Some experts and scholars, analyzed the recent developments in the region as democratic 
revolutions. These people usually consider the dictatorship and lack of politics as the root of political revolutions, and do not believe in much Islamic aspect for the recent developments. In this approach, the role of youth influenced by the West, women with non-Islamic attire, religious minorities and secular trends are pointed mainly out and it is underlined that the establishment of Islamic law and a theocracy were not the purpose of protestors. People of the region are seeking democracy and civil and political freedoms and are not affected by the Islamic Revolution in any way and never called for the establishment of the Islamic system. Civil, political, electoral, media freedoms and freedom of expression and political prisoners' freedom, were the most important demands of the people. So according to the writers influenced by the "Liberalism School", political and cultural revolutions in the Middle East and North Africa occurred due to the lack of democratic structures and civil freedoms and as a result of national awakening of the civil society in these governments and, particularly as a result of the effects of globalization through communication tools (ibid: 227).

Political developments of the Arab world as post-Islamism

Another analysis on the recent revolutions considered especially in the western academic circles, is the "post-Islamism" approach to the developments in the region. This approach is similar to the second approach, the developments in the region as democratic revolutions. However, its main emphasis is on deformation and transformation of Islamist movements in the region and the formation of democratic and human rights trends. In this field, Asef Bayat says "Religious movements have been participated in the protests in the Arab world, like al-Nahda in Tunisia or the Muslim Brotherhood in Egypt, but these revolutions were beyond the Islamic policies. Due to the growth of democratic movements and emotions in the Middle East, Islamists have resorted to post-Islamism methods that paves the way for a democratic change in the way in which the inclusive Islam can play a significant role. The result could be a postIslamist "revolution" (a mixture of reform and revolution). Post-Islamism is not anti-Islam or secular, but a movement that focuses on both religion and civil rights. It hopes the formation of a virtuous and pious society in the context of a democratic government (see Niakouei, 2012).
Hence, according to Asef Bayat, although in the recent uprisings in the region, most participants were religious and pious people, but religious slogans and discourses were mainly absent and protesters were demanding democracy in all revolutionary countries. Generally, people who have introduced the recent developments "postIslamism revolutions", emphasize the formation of new ideals and values like democracy, human rights and freedom among new Islamists and believe that the Islamic discourse in 1980s and 1990s which was based on the Islamic state and Sharia, has not such a good place among the protesters of Arab Societies, so the recent political developments are revolutions for democracy and human rights.

Therefore, it can be seen that there is no unified view on the recent developments in the Middle East and North Africa and the nature of these revolutions, and different ideas are applied to analyze the nature of the revolutions. Therefore, it seems that there is a kind of dispersion of thought on the analysis of the political developments. Now with an understanding of the research variables, we discuss the main theme of the research, role of social networks in the spread of the Arabic revolutions with an emphasis on developments in Tunisia, Egypt and Bahrain.

\section{Role of social networks in the spread of the Arabic revolutions}

Facebook and Twitter revolutions and generally social networks revolution is a new combination that has recently entered the political literature and sociology. It is easy to see that this combination stems from the recent events in the Middle East and North Africa which started from the developments in Tunisia and Egypt and spread to almost all areas of the Arab world. What is undeniable in these developments, is the impact of the internet and social networks in informing, organizing and rapid development in the countries of the region. Recent developments in the region reveals the fact that new technologies such as the internet and social networks were effective in rapid and sustainable spread of social changes. In the light of globalization, social networks such as Facebook and Twitter could serve the peoples' ideals and make a symbolic interaction between protest act of Arabic citizens and virtual media and structure. This interaction, linked the street and cyberspaces and formulated a protest discourse. Arabic spring not only challenged the 
dictatorships, but also empowered people to use new media technologies to create common values and support their revolution (Nazari and Gholipour, 2011: 52). The fact that these revolutions have been mainly popular and regional revolutions, and the digital tools and social media only enhanced the continuity and progress. Social networks, especially Facebook, had an effective role in organizing people and youth who have been the driving engine of the revolution. For example, organization of mass protests in Cairo, first was conducted by a group of young Egyptians on Facebook. Tunisia and then in other countries, such as Bahrain and Yemen had the same situation. More than 35 percent of Tunisians and more than 20 percent of Egyptians had Internet access. So, in Egypt and Tunisia, social networks like Twitter and Facebook have turned the engine of revolution on and accelerated it every day. However, the Bahraini people's uprising on February 14 started from the social networks and news of the events began to spread through these networks. Pages of Youth Coalition of February 14, the coalition of the day of anger, Bahraini students, Islamic Unity Society, etc. invited people to rallies and protests in Pearl Square, Manama and other cities in Bahrain in the midst of the country's revolution on February 14 (Ebrahimi, 2011: 129). The importance of social networks and the internet is such that Saudi king offered $\$ 150$ billion for the full purchase of Facebook and Twitter social networks, to distort the wave of Arab uprisings and prevent the proliferation of the uprisings to Saudi Arabia. Experts and researchers refer to social networks such as Facebook and Twitter as one of the important levers and weights of influence in the popular revolutions in the Middle East and North Africa. That's why, a short time after recent protests in Bahrain and Yemen, Facebook was filtered in the country, and the main page of Shiites in these countries, as the largest group of protestors, with hundreds of thousands of members was removed from this social network (Aghaei and others, 2012: 15-16). By effectively using new social media in different Arab countries and immediate reflection of the results of the revolutions in Tunisia and Egypt, the Arab world sees the rise of independent and vibrant social media, and steadily increasing citizens' participation in the internet, which is expected to attract about 100 million Arab users by 2015. New social networks create communication, organization and increase transparency and seek to hold governments accountable. Facilitating interactions and public relations in everyday life and providing tools for organizing the system of change and democratic political institutions, the new social media prove that they are the democratic factor (Cottel, 2011: 651). Due to the wide capacity and applications mentioned in the previous section of research, these networks made the necessary coordination between the youth and the demonstrators in the region. Communities captivated by dictatorships in Arab countries suffer from weak social bonds. The bonds that are basically not allowed by the government to be formed. But just when the repression of political parties and civil society organizations had destroyed any hopes for the formation of communication, cyberspaces suddenly arrived with powerful networks. Citizens who previously had no constructive social connection with each other, suddenly had the opportunity to communicate and form new bonds. The formation of social networks and derived bonds, suddenly released a stunning energy that the structure of authoritarian regimes, could not deal with.

According to the analysis of "The Arab Social Media Report", Facebook is the most popular social network in the Middle East and North Africa. This report believes that using Facebook is the first and most standard use of social media in the Arab region. According to the report, Facebook and Twitter users in all 22 Arab countries, shows the prominence of their role in civil movements that are present in all the region. Arab Social Media Report points out that social networks had four important functions in revolutionary developments in Arab countries: (1) Organizing the protests, (2) Disseminating the information, (3) Raising the awareness of events taking place locally and globally, (4) encouraging people to participate in protests and Civil movements (Aghaei and others, 2012: 17). In the Arabic spring, in 2011, social and media networks had an important role in the rapid decomposition of at least two of the region's regimes in Tunisia and Egypt, and also in the distribution and sociopolitical organization and mobilization in Bahrain, Libya, Jordan, Yemen, Saudi Arabia, Syria, etc. In this regard, Stepanova states that "Two important functions of social networks in the developments in the region are: (1) organizing the protests and (2) disseminating the information of 
developments in the region through international propaganda" (Stepanova, 2011: 2). Doctor Yusuf Jabarin, director of the Center for Arabic Studies of Law and Contemporary Politics, about two revolutions in Tunisia and Egypt believes that this uprising won with the slogan "No to violence" and relying on human rights, social justice and clean government and social equality. Jabarin believes that the common idea of "rebuilding the Arab character" through modern media in the Arab world, is developing in these revolutions (Jabarin, 3: 2011). Also, Abu Zaid, editorial director of "An-Nahar" in Yemen with a sociological point of view believes that the Arab youth today moved towards the cyberspace and the internet to gain their social and ontological existence and play an active role in political and social life; it means to challenge the Arab states on the internet. He believes that the Arab youth well used the globalization era and social networks for bringing this idea. Since a third of the population in the Arabic region are the people from 15 to 29 , the situation is different from the rest of the world. Abu Zaid said: "With the development of mass media and new mass communication tools and satellite channels like Al-Jazeera and taking shelter in social networks, in recent years, the young people are seeking relief from the walls of dictatorship." (Abu Zaid, 2011: 5). An opposition Arab activist (Huwaidi in Al-Khaleej newspaper) says: We use Facebook to schedule the protests, Twitter to coordinate, and YouTube to inform the world. One of the features of social networks is that the youth communicate with each other in the region without restrictions. Facebook, Twitter and YouTube allowed them to share different views without censorship and facilitate and exchange information. Social networks paved the way for something called the Yasmin Revolution or the Arab Spring. Much of the organization of the events related to Arabic movements in the cyberspace and social networks were carried out in the form of a declaration, call, news, information of the movement, the condition of the revolutionary and state forces, geographical-communicational locations and messages. For example, on Facebook, a page titled "Project to prepare a plane for each president" was set up that was an irony for the Arab leaders and dictatorships. On this page, Hosni Mubarak, Ben Ali and other dictators in the region were asked to think about packing their suitcases. Al-Jazeera, in a report titled "The headquarters of the Libyan revolution" in recent years, pointed out the strong role of social networks and virtual communities in Libya's revolution, so that the Libyan Revolution was called "cyber riot" in this report. When in the early days of the revolution, Gaddafi banned the entry of journalists into the soil of Libya, images and contents of that broadcasted on YouTube soon. They also cited the Libyan rebels attack with heavy weapons. YouTube News International Union, despite the absence of foreign journalists, released clear images and evidence of human rights abuse and humanitarian disaster happening. Thus, the responsibility for tracking was raised at the International Criminal Court. However, the important point is that new and traditional media can be considered effective and essential to alert the world public opinion against the repressive and inhumane acts such as those that took place in the collective revolutions, and can even be a General Court to examine the moral and practical considerations related to human military interventions (Cottel, 2011: 656). Arabic revolutions are known with this remarkable fact that social unrests will not be confined to a particular country and will be spread to other countries. The initial protests in Tunisia was quickly spread across the Middle East and North Africa. However, it is observed that information and communication technologies played a decisive role in the expansion of regional developments in the Middle East and North Africa. Youth and social network forces opposed to authoritarianism could exploit globalization technological tools to achieve their goals and overthrow the dictatorships. If we accept that the pen is mightier than the sword, today we can say that "click" is more powerful than firearms and cold weapons (Howard and Hussain, 2011: 44). In general, it can be said that the information and communication technologies in the era of globalization had a very effective role in the expansion and acceleration of political developments in the region. Youth and political activists in these countries could exploit globalization technological tools like social networks to achieve their goals.

\section{Conclusion}

Acknowledging that the social networks had a decisive effect on the development of the Arabic revolution, this article tried to explore the issue. Therefore, this article tried its best to find the 
response to this question: "What was role of the social networks in the expansion of revolutionary developments in the Middle East and North Africa?" In response to this question, we hypothesized that the internet and particularly social networks, raised the awareness among people and social forces involved in the region, particularly young people, have drawn their attention to what was happening around them and facilitated and accelerated the process of regional developments. To examine this assumption, in terms of theoretical foundations, the article focused on the structuration theory of Anthony Giddens. On this basis, the Arab youth as revolutionary agents utilized the technological structure and overthrew the existing dictatorships. The era of globalization as the most recent paradigm ruling the human life, brought modern tools and achievements for people. Internet and social networks are of the most important tools that have found many applications in the recent decades. Therefore, the developments in the Middle East and North Africa indicate the strong role of new technologies in the formation and the spread of the Arabic revolutions so that some have called them Facebook revolutions. Thus, the people in these countries rose up to participate in the destiny of their country and declared their discontent and protest to the dictatorial rulers and were successful. It is said that 2011 was the year of social networks in the expansion of revolutionary developments in the Middle East and North Africa.

\section{References}

Aghaei and others, Seyed Davoud 2012, "The Internet and new social media and developments in the Middle East", Journal of Foreign Affairs, the $4^{\text {th }}$ year, No. 2.

Abolfat'hi, Mohammed; Nouri, Mokhtar 2012, "Revolutionary developments in the Middle East and national security of the Islamic Republic of Iran", Journal of Islamic Awakening, the $1^{\text {st }}$ year, No. 3.

Ebrahimi, Nabiollah 2011, "The impact of social networks and satellite channels in the development of the Arabic revolution", Journal of Strategic Studies, the $4^{\text {th }}$ year, No. 2 .

Abu Zaid, Jihan 2011. "Youth and developmental goals in the Arab world", Sanaa.

Bashiriyeh, Hossein (2000), "Introduction," in the contemporary political sociology book, edited by
Kate Nash, translated by MT delightful, Tehran: Kavir Publication.

Haji Nasseri, Saeed and Asadi Haghighi, Ebrahim 2012. "Analysis of the new middle class in the social movement in Egypt", Journal of Foreign Affairs, the $4^{\text {th }}$ year, No. 4 .

Jabarin, Yusef 2011. "The most important achievement of Arab revolutions, rebuilding an Arab human challenger, Cairo: Arab Centre for Rights and Posterior policies.

Rafi, Hossein and Janbaz, Dian 2010. "The Impact of global information and communication technologies on national security", Journal of Politics, Vol. 40.

Rasouli Sani Abadi, Elham 2013. "Examining the revolutionary developments in the Arab countries from the perspective of liberalism, constructivism and critical theory of international relations", Journal of Foreign Affairs, No. 2.

Sardarnia, Khalilollah 2008. "Internet, social movements and the mobilization of protests (Theoretical and exemplary analysis of several social movements), Journal of Political and International Approaches, No. 16.

Kia, Ali Asghar and Mahmoudi, Abdolhamid 2011. "The role of social networks in Tunisia", monthly journal of political-economic information, $25^{\text {th }}$ year, No. 283.

Moshirzadeh, Homeira 2006. "The development in theories of international relations", Tehran: Samt Publication.

Niakouei, Seyed Amir 2012. "Dissection of contemporary revolutions in the Arab world, Tehran: Mizan Publication.

Nazari, Ali Ashraf; Gholipour, Mojtaba 2011. "The Relationship as the revolution of modern information-communication technology and revolutionary movement in Egypt", Proceedings of the Conference on Islam and geopolitical developments in the Middle East and North Africa, Tehran: Iran geopolitical community.

Yazdanfam, Mahmoud 2011. "Developments in the Arab world: the formation of power and identity in the Middle East", Journal of Strategic Studies, No. 2 .

Waters, Malcom 1379. "Globalization", translated by Ismail Mardani Givi and Siavash Moridi, Tehran: Publication of Industrial Management Institute. 


\section{Role of Social Networks}

Cottle, Simon 2011. Media and the Arab uprisings of 2011: research notes, Cardiff University: UK, sagepub.

Eriksson, Johan and Giacomoll, Giampieero 2006. International Relation and Security in Digital Age, New York: routledge.

Howard, P.N and Muzammil, Hussain 2011. The upheavals in Egypt and Tunisia: the role of digital media, journal of Democracy, vol 22, no3.

Robertson, R 1992. Globalization: social Theory and Global culture, sage: London.

Stepanova, Ekaterina 2011. The role of communication technologies in the Arab spring, Institute of world economy and international relation, Russian academy of science.

Sadeghi, S., \& Voneiff, G. 2013. A Well Perfor-mance Model Based on Multivariate Analysis of Completion and Production Data from Horizontal Wells in the Montney Formation in British Columbia. In SPE Unconventional Resources Conference Canada, Calgary: onepetro.

Sadeghi, S., \& Voneiff, G. 2014. Probabilistic Forecasting of Horizontal Well Performance in Unconventional Reservoirs Using Publicly-Available Completion Data. In SPE Unconventional Resources Conference. woodlands, TX: onepetro. 